\title{
Produção de mudas de pequizeiro sob diferentes métodos de quebra de dormência
}

A produção de mudas de pequizeiro (Cariocar brasiliense) por meio de sementes é afetada diretamente pela presença de dormência. Em função disso, o presente trabalho teve como objetivo avaliar técnicas de quebra de dormência de unidades de dispersão (putâmen) de pequi, utilizando métodos mecânicos (escarificação) e tratamento fitohormonal com ácido giberélico. Para tal, instalou-se em viveiro um experimento com delineamento de blocos ao acaso, em esquema fatorial $3 \times 3$ e quatro repetições. Os frutos foram coletados maduros logo após sua queda. Retirou-se o epicarpo e mesocarpo, obtendo o putâmen. Os tratamentos consistiram na utilização de putâmens escarificados e não escarificados, imersos por 96 horas em solução de ácido giberélico nas doses de 1, 2 e $3 \mathrm{~g}$ dm-3. Após o surgimento da primeira plântula, determinou-se o tempo médio de emergência de plântulas, índice de velocidade de emergência e o percentual de emergência. As doses de ácidos giberélicos influenciaram na porcentagem de germinação, independentemente do método de escarificação, sendo as doses de 2 e 3 g.dm- 3 que proporcionaram melhores resultados. Os tratamentos com escarificação em 1 e 2 faces da semente proporcionaram melhores resultados de percentagem de germinação, em comparação ao não escarificado.

Palavras-chave: Caryocar brasiliense; Propagação de planta; Fitohormônio; Cerrado.

\section{Production of pequi tree seedlings under different dormancy breaking methods}

\begin{abstract}
The production of pequizeiro seedlings (Cariocar brasiliense) through seeds is directly affected by the presence of dormancy. As a result, the present study aimed to evaluate techniques for breaking dormancy of dispersion units (putamen) of pequi, using mechanical methods (scarification) and phytohormonal treatment with gibberellic acid. To this end, an experiment was set up in a nursery with a randomized block design, in a $3 \times 3$ factorial scheme and four replications. The fruits were collected ripe soon after their fall. The epicarp and mesocarp were removed, obtaining the putamen. The treatments consisted of using scarified and nonscarified putamens, immersed for 96 hours in gibberellic acid solution in doses of 1,2 and $3 \mathrm{~g} \mathrm{dm}-3$. After the appearance of the first seedling, the mean seedling emergence time, emergence speed index and the emergence percentage were determined. The doses of gibberellic acids influenced the germination percentage, regardless of the scarification method, with the doses of 2 and 3 g.dm-3 providing the best results. The treatments with scarification on 1 and 2 faces of the seed provided better results of percentage of germination, in comparison to the non-scarified.
\end{abstract}

Keywords: Caryocar brasiliense; Plant propagation; Phytohormone; Cerrado.

Topic: Conservação da Biodiversidade

Reviewed anonymously in the process of blind peer.
Received: 04/07/2021

Approved: 27/07/2021
Leandro Oliveira Campos (iD)

Instituto Federal do Tocantins, Brasil

http://lattes.cnpq.br/8341309942617933

http://orcid.org/0000-0001-9476-0227

leandro.campos@ifto.edu.br

Ruy Borges da Silva

Instituto Federal do Tocantins, Brasil

http://lattes.cnpq.br/8027193528690563

ruyborges@ifto.edu.br

Rafael Gomes da Mota Gonçalves (iD

Universidade Federal Rural do Rio de Janeiro, Brasil

http://lattes.cnpq.br/0244672026134100

http://orcid.org/0000-0001-9541-6698

rafaelmotag@gmail.com
Soraya Freitas Silva

Instituto Federal Goiano, Brasil

http://lattes.cnpq.br/2594865414691446

soraya_freitas-agro@hotmail.com
Referencing this:

CAMPOS, L. O.; SILVA, R. B.; GONÇALVES, R. G. M.; SILVA, S. F..

Produção de mudas de pequizeiro sob diferentes métodos de quebra de dormência. Revista Ibero Americana de Ciências Ambientais, v.12, n.7, p.148-154, 2021. DOI: http://doi.org/10.6008/CBPC21796858.2021.007.0014 


\section{INTRODUÇÃO}

A produção de mudas de frutíferas nativa do cerrado por meio de propagação sexuada vem se tornando uma importante alternativa de conservação frente à crescente devastação da vegetação. Dentre as espécies ameaçadas, tem-se o pequi (Caryocar brasiliense), planta arbórea que pode apresentar cerca de 10 metros de altura, com troncos grossos, cascas cinzentas, e frutos com elevado potencial econômico (ALMEIDA et al., 1998).

O fruto do pequi caracteriza-se geralmente pela presença de um a quatro caroços (pirênio ou putâmen) (ALMEIDA et al., 1994), cor verde, com uma a quatro sementes, comprimento do fruto variando de $6 \mathrm{~cm}$ a $14 \mathrm{~cm}$ e massa em torno de $100 \mathrm{~g}$ a $300 \mathrm{~g}$ (BERNARDES et al., 2008). Ressalta-se ainda a grande aceitação da polpa dos frutos para fins culinários, além na preparação de licores caseiros e extração de óleos para a fabricação de sabão e tratamento de doenças respiratórias (ALMEIDA et al., 1994).

A presença de dormência e a baixa velocidade de germinação das sementes de pequi são fatores que interferem na produção de mudas. Alguns estudos afirmam que os períodos de emergência podem variar de um a seis meses (MELO, 1987; OLIVEIRA, 1998). Essa dormência das sementes do pequizeiro deve-se principalmente a impedimentos físicos, causados pelo endocarpo, e fisiológicos, decorrentes da presença de inibidores químicos no embrião e pela incapacidade deste em mobilizar reservas da semente (DOMBROSKI et al., 1998). A dormência nas sementes de pequi contribui para uma grande desuniformidade no processo germinativo, dificultando a sua propagação (PEREIRA et al., 2001; VIEIRA et al., 2004).

Para superar este entrave, os usos de métodos de quebra de dormência são fundamentais. A escarificação e a remoção dos envoltórios das sementes são tratamentos usados para melhorar a taxa de emergência (MELO, 1987), porém, maiores resultados podem ser alcançados com o uso de tratamento fitohormonal, com o ácido giberélico (DOMBROSKI, 1998). Estudando o efeito de inibidores na dormência de sementes de pequi (Caryocar brasiliense), Melo (1987) afirma que existe efeito prejudicial das camadas envoltórias nas sementes de pequi, e que com a escarificação ou eliminação obteve-se um aumento de $12 \%$ na taxa de emergência. Leão et al. (2012) estudando a produção de mudas de pequizeiro através do uso de ácido giberélico ( $500 \mathrm{mg} . \mathrm{L}^{-1}$ por 48 horas), afirmam que a percentagem de emergência oscilou de 5 a $57 \%$ e o tempo médio de emergência de 29 a 72 dias.

Dentro deste contexto, o presente trabalho teve como objetivo avaliar técnicas de quebra de dormência de unidades de dispersão (putâmen) de pequi, utilizando métodos mecânicos (escarificação) e tratamento fitohormonal com ácido giberélico.

\section{MATERIAIS E MÉTODOS}

O experimento foi conduzido no viveiro do Instituto Federal do Tocantins Campus Araguatins, no período de dezembro de 2015 a abril de 2016. De acordo com o método de Thornthwaite o clima é classificado como úmido com pequena deficiência hídrica ( $\left.22 \mathrm{rA}^{\prime} \mathrm{a}^{\prime}\right)$, caracterizando evapotranspiração potencial anual de $1.700 \mathrm{~mm}$, distribuindo-se no verão em torno de $500 \mathrm{~mm}$ ao longo dos três meses 
consecutivos com temperatura mais elevada. A precipitação média anual varia de 1.400 a $1.500 \mathrm{~mm}$ (SEPLAN, 2008).

Instalou-se o experimento em viveiro que possui tela de sombreamento de $50 \%$ na cobertura e laterais protegidas com tela sombreamento de $50 \%$.

As unidades de dispersão (putâmens) de pequizeiro (Caryocar brasiliense), foram coletadas de diferentes plantas de uma população natural ocorrente no cerrado no município de Araguatins no mês de dezembro/2015. Os putâmens são provenientes de frutos caídos no chão, sendo que se retirou o epicarpo (casca).

Para a extração do mesocarpo (polpa) os putâmens foram armazenados por um período de 4 dias para facilitar a sua remoção. Em seguida, foram colocados em uma caixa plástica perfurada, para serem lavadas em água corrente. Inicialmente, foram levadas ao sol por um período de duas horas, sendo a secagem concluída a sombra durante três dias. Para instalação do experimento foram selecionadas, em função do tamanho e sanidade (apenas visual), 450 putâmens.

Os testes de emergência foram efetuados com putâmens escarificados em 1 e 2 faces, e não escarificados, submetidos à imersão por 96 horas em solução de ácido giberélico nas doses de 1, 2 e 3 g.dm 3 , adotando-se o esquema fatorial 3x3, totalizando 9 tratamentos, no delineamento de blocos ao acaso, com quatro repetições.

A escarificação foi efetuada por um corte longitudinal realizado no putâmen com o auxílio de uma serra manual e esmeril. As soluções do fito-hormônio foram preparadas com o produto comercial ProGibb ${ }^{\circledR}$ 400, diluído em água potável.

Tabela 1: Tratamento de separação de dormência.

\begin{tabular}{|c|c|}
\hline $\begin{array}{l}\text { Tratament } \\
\text { o }\end{array}$ & Procedimento \\
\hline T1 & Putâmen sem escarificação + imersão em solução de ácido giberélico na dose de 1 g.dm-3 \\
\hline $\mathrm{T} 2$ & Putâmen sem escarificação + imersão em solução de ácido giberélico na dose de 2 g.dm-3 \\
\hline T3 & Putâmen sem escarificação + imersão em solução de ácido giberélico na dose de 3 g.dm-3 \\
\hline T4 & Putâmen escarificado com esmeril em uma face + imersão em solução de ácido giberélico na dose de 1 g.dm-3. \\
\hline T5 & Putâmen escarificado com esmeril em uma face + imersão em solução de ácido giberélico na dose de 2 g.dm-3. \\
\hline T6 & $\begin{array}{l}\text { Putâmen escarificado com esmeril em uma face + imersão em solução de ácido giberélico na dose de } 3 \mathrm{~g} . \mathrm{dm}-3 \text {. } \\
\text { Putâmen escarificado com lâmina de serra em duas faces + imersão em solução de ácido giberélico na dose de } 1 \mathrm{~g} . \mathrm{dm} \text { - }\end{array}$ \\
\hline T7 & $\begin{array}{l}\text { 3. } \\
\text { Putâmen escarificado com lâmina de serra em duas faces + imersão em solução de ácido giberélico na dose de } 2 \mathrm{~g} . \mathrm{dm} \text { - }\end{array}$ \\
\hline T8 & $\begin{array}{l}\text { 3. } \\
\text { Putâmen escarificado com lâmina de serra em duas faces + imersão em solução de ácido giberélico na dose de } 3 \text { g.dm- }\end{array}$ \\
\hline T9 & 3. \\
\hline
\end{tabular}

Os tratamentos foram dispostos na área experimental (canteiro de germinação). Cada parcela experimental foi constituída por uma fileira com 10 sementes.

O plantio foi realizado no dia 10 janeiro de 2016 em canteiro de germinação contendo areia lavada como substrato. A semeadura foi realizada a uma profundidade de $6 \mathrm{~cm}$, sendo irrigado diariamente, mantendo o substrato sempre úmido. A emergência foi avaliada diariamente após o surgimento da primeira plântula (58 dias) durante 70 dias após a semeadura, obtendo-se o tempo médio de emergência, o índice de velocidade de emergência e o percentual de emergência. O tempo médio de emergência foi estimado 
conforme medotologia de Edmond et al. (1958) descrita por Oliveira (2012).

$$
T M=\frac{E 1 T 1+E 2 T 2+\cdots+E i T i}{E 1+E 2+E 3}
$$

Onde:

TM é o tempo médio necessário para atingir a emergência máxima (dias); E1 até Ei é o número de emergência ocorrida a cada dia; T1 até Ti é o tempo (dias).

O índice de velocidade de emergência (IVE) foi calculado de acordo com a fórmula de Maguire descrita por Oliveira (2012).

$$
I V E=\frac{E 1}{T 1}+\frac{E 2}{T 2}+\cdots+\frac{E i}{T i}
$$

Onde:

IVE é o índice de velocidade de emergência; E1 até Ei é o número de emergência ocorrida a cada dia; T1até Ti é o tempo (dias). A porcentagem de plântulas emergidas até os 60 dias após a semeadura foram transformados para arcoseno $\sqrt{\%}$.

A análise estatística dos dados do tempo médio de emergência de plântulas (TM) foram submetidos a estatística descritiva e análise de variância. Enquanto o índice de velocidade de emergência e o percentual de emergência foram submetidos a análise de variância e as médias comparadas pelo teste de Tukey a 5 \% de significância. Nesta etapa utilizou-se o programa estatístico Assistat.

\section{RESULTADOS E DISCUSSÃO}

Os valores da percentagem de emergência (EMER) e índice de velocidade de emergência (IVE) estão apresentados na Tabela 2 . Verifica-se que houve efeito significativo $(p<0,01)$ para o fator escarificação e dose de ácido giberélico sobre a EMER e IVE de plântulas de $C$. brasiliensis, além de interação significativa entre ambos fatores analisados.

Tabela 2: Quadrados médios da percentagem de emergência (EMER) e índice de velocidade de emergência (IVE) de

\begin{tabular}{|c|c|c|c|}
\hline Fontes de variação & $\mathrm{GL}$ & Quadrados I & \\
\hline & & EMER.1 & IVE \\
\hline Escarificação (A) & 2 & $1.000,53 * *$ & $0,00243 * *$ \\
\hline Dose Ácido Giberélico (B) & 2 & $338,03 * *$ & $0,00110 * *$ \\
\hline$(A \times B)$ & 4 & $94,65 * *$ & $0,00025 * *$ \\
\hline Blocos & 3 & $4,22 n s$ & $0,00001 \mathrm{~ns}$ \\
\hline Resíduo & 24 & 33,16 & 0,00009 \\
\hline Total & 35 & -- & -- \\
\hline C.V. (\%) & -- & 41,8 & 43,95 \\
\hline
\end{tabular}
sementes de C. brasiliensis.

* Significativo ao nível de $5 \%$ de probabilidade pelo teste $\mathrm{F}$;

** Significativo ao nível de $1 \%$ de probabilidade pelo teste F;

${ }^{\text {ns }}$ Não significativo

${ }^{1}$ Variáveis transformadas pelo arco seno $\sqrt{\frac{X}{100}}$.

Os desdobramentos das interações significativas dos tratamentos (escarificação $\mathrm{x}$ dose de ácido giberélico) encontram-se nas Tabelas 3 e 4.

Para a variável percentagem de emergência (Tabela 3) verifica-se que as doses de 2 e $3 \mathrm{~g} \mathrm{dm}^{-3}$ promoveram melhor desempenho da emergência das plântulas, independentemente da escarificação mecânica adotado. Os valores médios da percentagem de emergência foram de 17,8\% e 20,3\%, respectivamente, para as doses de 2 e $3 \mathrm{~g} \cdot \mathrm{dm}^{-3}$. 
Quando se avalia o método de escarificação dentro das doses, percebe-se a sua efetividade, nas doses 2 e 3 g.dm ${ }^{-3}$, obtendo-se uma percentagem de emergência de 23,3\% e 27,5\%, respectivamente.

Tabela 3: Valores médios da percentagem de emergência (EMER) de sementes de C. brasiliensis, em função da escarificação e doses de ácido giberélico.

\begin{tabular}{|c|c|c|c|c|}
\hline Dose de ácido giberélico (g.dm-3) & Sem escarificação & 1 face & 2 faces & Média \\
\hline & \multicolumn{4}{|c|}{ |----------------------------------- \%-------------------------------- } \\
\hline 1 & $0,0 \mathrm{bA}$ & $10,0 \mathrm{bA}$ & $0,0 \mathrm{bA}$ & $3,3 \mathrm{~b}$ \\
\hline 2 & $10,0 \mathrm{abB}$ & 23,3 aA & 20,0 Aab & $17,8 \mathrm{a}$ \\
\hline 3 & $13,3 \mathrm{aB}$ & $20,0 \mathrm{abAB}$ & 27,5 aA & $20,3 \mathrm{a}$ \\
\hline Média & $7,8 \mathrm{~B}$ & $17,8 \mathrm{~A}$ & $15,8 \mathrm{~A}$ & \\
\hline
\end{tabular}

As médias seguidas pela mesma letra minúscula, na coluna, e mesma letra maiúscula, na linha, não diferem estatisticamente entre si, pelo Teste de Tukey ao nível de um $1 \%$ de probabilidade.

Os dados do índice de velocidade de emergência (IVE) apresentados na tabela 4, tiveram comportamento semelhante a variável de percentagem de emergência.

As doses de 2 e $3 \mathrm{~g} \cdot \mathrm{dm}^{-3}$ de ácido giberélico proporcionaram maior vigor das plântulas, independentemente do método de escarificação aplicado à semente. Os valores médios do IVE para os respectivos tratamentos foram de 0,0254 e 0,0328. A escarificação das sementes de pequizeiro nas duas faces permitiu um maior IVE, principalmente quando se aplicou a dose de $3 \mathrm{~g} \mathrm{dm}^{-3}$. Do ponto de vista de germinação, tais resultados são considerados baixos.

Resultados diferentes deste estudo foram encontrados por Silva et al. (2006) quando estudaram a emergência de plântulas de pequi, obtendo IVE variando de 0,03 a 0,08 para putâmens escarificados e 0,08 a 0,10 para putâmens não escarificados.

Tabela 4: Valores médios do índice de velocidade de emergência (IVE) de sementes de C. brasiliensis, em função da escarificação e doses de ácido giberélico.

\begin{tabular}{lllll}
\hline Dose de ácido giberélico (g.dm-3) & Não escarificada & 1 face & 2 faces & Média \\
\hline 1 & $0,0000 \mathrm{bA}$ & $0,0159 \mathrm{bA}$ & $0,0000 \mathrm{cA}$ & $0,0053 \mathrm{~b}$ \\
2 & $0,0130 \mathrm{abB}$ & $0,0375 \mathrm{aA}$ & $0,0257 \mathrm{bAB}$ & $0,0254 \mathrm{a}$ \\
3 & $0,0190 \mathrm{aB}$ & $0,0348 \mathrm{aAB}$ & $0,0447 \mathrm{aA}$ & $0,0328 \mathrm{a}$ \\
Média & $0,0107 \mathrm{~B}$ & $0,0294 \mathrm{~A}$ & $0,0235 \mathrm{~A}$ & -- \\
\hline
\end{tabular}

As médias seguidas pela mesma letra minúscula, na coluna, e mesma letra maiúscula, na linha, não diferem estatisticamente entre si, pelo Teste de Tukey ao nível de um $1 \%$ de probabilidade.

O tempo para emergência das plântulas variou de 57 a 88 dias, atingindo uma média de 66 dias no período avaliado (Tabela 5). Conforme a classificação de Ferreira et al. (2001), o pequi pode ser classificado como espécie de germinação lenta (tempo médio > 10 dias), constituindo um bom índice para se avaliar a rapidez de ocupação da espécie em um determinado nicho ou território.

Tabela 5: Valores médios, mínimos e máximos para o tempo médio de emergência (TM), em dias, em plântulas de progênies de pequizeiro provenientes da região Norte do Tocantins, coletadas na safra 2015.

\begin{tabular}{ll}
\hline Valores & Tempo médio de emergência (TM) \\
\hline Média & 66 \\
Mínimo & 57 \\
Máximo & 88 \\
CV (\%) & 12,1 \\
\hline
\end{tabular}

CV\%: Coeficiente de variação.

Leão et al. (2012) estudando a produção de mudas de pequizeiro através da emergência de sementes oriundas de 16 plantas, aos dez meses após a colheita, na presença e ausência de ácido giberélico (500 mg.L 
${ }^{1}$ por 48 horas), afirmam que encontraram interação significativa entre genótipo e o tratamento, sendo que a percentagem de emergência oscilou de 5 a 57\% e o tempo médio de emergência de 29 a 72 dias.

Diversos estudos demonstraram que o tempo pode variar de um mês a mais de um ano e a porcentagem de germinação de 5\% a 60\% (FERNANDES et al., 2005; RODRIGUES et al., 2007; ROCHA et al., 2009). De acordo com Rocha (2009), a produção de mudas em larga escala de pequizeiro via sementes é um grande desafio, principalmente devido sua desuniformidade e à baixa taxa e velocidade de germinação das sementes.

Em outro trabalho desenvolvido por Rocha (2009), afirma que fatores ambientais como a amplitude térmica, umidade relativa do ar e precipitação pluviométrica devem ser considerados também durante a produção de mudas de pequizeiro. Destaca-se ainda o efeito da progênie (MOURA, 2012), qualidade do embrião (RODRIGUES et al., 2007), tempo de armazenamento, ataque de insetos e tratamento com ácido giberélico (ROCHA et al., 2009).

Trabalho conduzido por Vieira et al. (2005) observaram resultados insatisfatórios de germinação de sementes de $C$. brasiliensis, provavelmente devido ao ataque de broca (Carmenta sp), estimada em 10\%, e/ou aos danos mecânicos provocados pelo método de escarificação, que foi estimado em 18\%.

No presente estudo observou-se a ocorrência de fungos durante o processo de remoção do mesocarpo e secagem dos putâmens, o que pode ter contribuído para o baixo vigor das sementes. De acordo com Pinto (1997), na propagação de espécies nativas, ainda não se tem amplo conhecimento da forma adequada de controle dos fungos, o que dificulta a produção em grande quantidade de mudas. Tais microrganismo podem afetar a qualidade fisiológica de diversas sementes, causando podridões e morte de plântulas em pré e pós-emergência, afetando diretamente a produção de mudas.

Além desses fatores que colaboraram com baixa emergência das sementes, pode-se salientar a qualidade do embrião, principalmente no tocante a maturidade fisiológica. Segundo Silva et al. (2006) provavelmente a dormência em pequi esteja relacionada ao um mecanismo intrínseco, uma vez que a sua dormência parece estar relacionada ao embrião imaturo.

Durante a produção de mudas de pequí, o tempo necessário para a germinação das sementes é resultante de um comportamento assincrônico da espécie, que evita a mortalidade total de plântulas em razão da ocorrência momentânea de condições de estresse que comprometam a sobrevivência, como as condições climáticas adversas ou o ataque de patógenos (MOURA, 2012).

\section{REFERÊNCIAS}

ALMEIDA, S. P.; SILVA, J. A.. Pequi e buriti: importância alimentar para a população dos Cerrados. Planaltina: Embrapa Cerrados, 1994.

ALMEIDA, S. P.; PROENCA, C. E. B.; SANO, S. M.; RIBEIRO, J. F.. Cerrado: espécies vegetais úteis. Planaltina: EmbrapaCPAC, 1998.

BERNARDES, T. G.; NAVES, R. V.; REZENDE, C. F. A.; BORGES, J. D.; CHAVES, L. J.. Propagação sexuada do pequizeiro (caryocar brasiliense camb.) estimulada por ácido giberélico. Pesquisa Agropecuária Tropical, v.38, n.2, p.71-77, 2008.

DOMBROSKI, J. L. D.; PAIVA, R.; CAMARGO, I. P.. Efeito de escarificação sobre a germinação de pequizeiro (Caryocar brasiliense Camb.). Revista Brasileira de Fruticultura, Cruz das Almas, v.20, n.1, p.7-14, 1998.

EDMOND, J. B.; DRAPALA, W. J.. The effects of temperature, sand and soil, and acetone on germination of okra seed. 
Proceedings of the American Society for Horticultural Science, n.71, p.428-434, 1958.

FERNANDES, J. S. C.; SOUZA, C. V.; OLIVEIRA, M. N. S.; DIAS, B. A. S.. Efeito de matrizes na germinação de sementes em pequizeiro (Caryocar brasiliense Camb.). In: CONGRESSO BRASILEIRO DE MELHORAMENTO DE PLANTAS, 3. Anais. Gramado: SBMP, 2005.

FERREIRA, A. G.; CASSOL, B.; ROSA, S. G. T.; SILVEIRA, T. S.; STIVAL, A. L.. Germinação de sementes de asteraceae nativas no Rio Grande do Sul, Brasil. Acta Botânica Brasílica, v.15, n.2, p.231-242, 2001. DOI: http://doi.org/10.1590/S0102-33062001000200009

LEÃO, E. F.; PEIXOTO, N.; MORAIS JÚNIOR, O.. Emergência de plântulas de pequizeiro em função da planta matriz e uso de ácido giberélico. Pesq. Agropec. Trop., Goiânia, v.42, n.4, p.416-423, 2012.

MELO, J. T.. Fatores relacionados com a dormência de sementes de pequi (Caryocar brasiliense Camb.). Dissertação (Mestrado em Ciências Florestais) - Escola Superior de Agricultura Luiz de Queiroz, Piracicaba, 1987.

MOURA, N. F.. Caracterização de frutos e progênies de pequizeiro (Caryocar brasiliense Camb.) do Cerrado. Tese (Doutorado) - Universidade Federal de Goiás, Goiânia, 2012.

OLIVEIRA, O. S.. Tecnologia de sementes florestais: espécies nativas. Curitiba: UFPR, 2012.

OLIVEIRA, K. A. K. B.. Variabilidade genética entre e dentro de populações de pequi (Caryocar brasiliense Camb.) do Estado de Goiás. Dissertação (Mestrado em Agronomia) Universidade Federal de Goiás, Goiânia, 1998.

PEREIRA, A.V.; PEREIRA E. B. C.; JUNQUEIRA, N. T. V.. Propagação e domesticação de plantas nativas do cerrado com potencial econômico. Horticultura Brasileira, v.19, n.2, 2001.
PINTO, N. F. J. A.. Eficiência de fungicidas no tratamento de sementes de milho visando o controle de Fusarium moniliforme e Pythium sp. Pesquisa Agropecuária Brasileira, v.32, p.797-801, 1997

ROCHA, J. P.. Fatores genéticos e ambientais na emergência de plântulas de pequizeiro (Caryocar brasiliense camb.). Dissertação (Mestrado) Universidade Federal dos Vales do Jequitinhonha e Mucur, Diamantina, 2009.

ROCHA, J. P.; FERNANDES, J. S. C.. Fatores ambientais e genéticos na germinação de sementes de pequizeiro (Caryocar brasiliense Camb.). In: CONGRESSO BRASILEIRO DE MELHORAMENTO DE PLANTAS, 5. Anais. Guarapari, 2009.

RODRIGUES, F. S.; NEIVA, I. P.; FERNANDES, J. S. C.. Germinação de sementes de pequizeiro de diferentes procedências e progênies plantadas diretamente no campo. In: SIMPÓSIO DE PESQUISA EM CIÊNCIAS AGRÁRIAS NO SEMI-ÁRIDO MINEIRO, 1. Anais. 2007, 2007. p.92.

SEPLAN. Secretaria do Planejamento e Meio Ambiente Tocantins. Diretoria de Zoneamento Ecológico - Econômico. Atlas do Tocantins: Subsídios ao planejamento da gestão territorial. Palmas: SEPLAN, 2008.

SILVA, M. A. P.; MEDEIROS FILHO, S.. Emergência de plântulas de pequi (Caryocar coriaceum Wittm). UFC, Ceará. Revista Ciência Agronômica, v.37, n.3, p.381-385, 2006.

VIEIRA, F. A.; GUSMÃO, E.; LOPES, P. S. N.. Uso do ácido giberélico na superação da dormência de sementes de pequizeiro (Caryocar brasiliense Camb.). In: CONGRESSO NACIONAL, 55; ENCONTRO REGIONAL DE BOTÂNICOS DE $M G, B A$ e ES, 26. Anais. Viçosa: Sociedade Brasileira de Botânica, 2004.

VIEIRA, F. A.; PACHECO, M. V.; LOPES, P. S. N.. Método de escarificação de putâmens de Caryocar brasiliense Camb. FAEF. Revista Científica Eletrônica de Agronomia, v.4, n.08, 2005.

A CBPC - Companhia Brasileira de Produção Científica (CNPJ: 11.221.422/0001-03) detém os direitos materiais desta publicação. Os direitos referem-se à publicação do trabalho em qualquer parte do mundo, incluindo os direitos às renovações, expansões e disseminações da contribuição, bem como outros direitos subsidiários. Todos os trabalhos publicados eletronicamente poderão posteriormente ser publicados em coletâneas impressas sob coordenação da Sustenere Publishing, da Companhia Brasileira de Produção Científica e seus parceiros autorizados. Os (as) autores (as) preservam os direitos autorais, mas não têm permissão para a publicação da contribuição em outro meio, impresso ou digital, em português ou em tradução. 